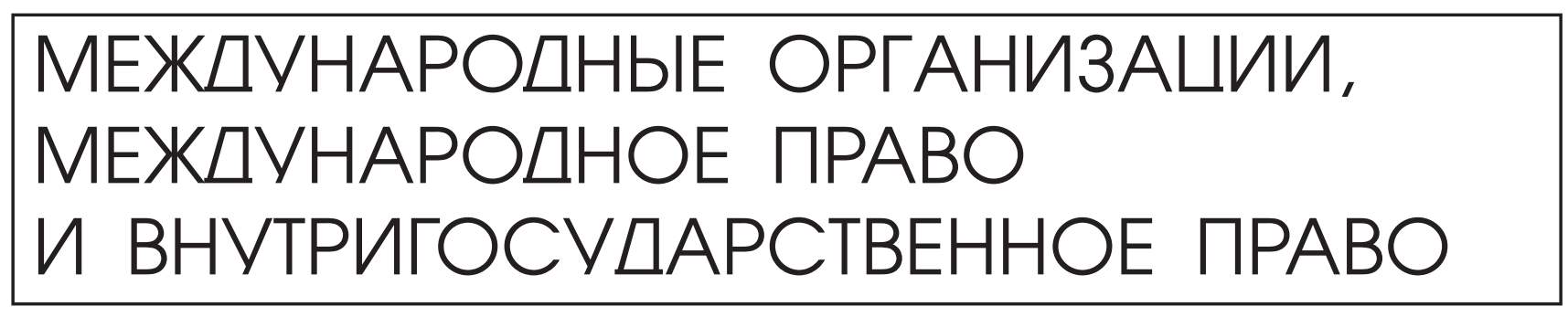

Осавелюк А.М.

\title{
ЯВЛЯЮТСЯ ЛИ МЕЖДУНАРОДНЫЕ ДОГОВОРЫ ИСТОЧНИКАМИ КОНСТИТУЦИОННОГО ПРАВА РОССИИ?
}

\begin{abstract}
Аннотация. Международные договоры Российской Федераџии наряду с общепризнанными принципами и нормами международного права являются в соответствии с Конституцичй Российской Федерации составной частью ее правовой системы (ч. $4 \mathrm{~cm}$. 15). Проблема принадлежности международных договоров к источникам конститучионного права не получила в отечественной литературе однозначного отношения. Как следствие, в статье на основе анализа научной литературы, действующего конституционного законодательства России и зарубежных государств, а также соответствуюших постановлений Конституционного Суда РФ предпринята попытка показать место международных договоров в системе конституциионного права. Автор считает, что вопрос о том, являются ли международные договоры Российской Федерации источниками конституичионного права России, действуют ли они на ее территории непосредственно и какова вообще их юридическая сила не имеет однозначного решения в силу того, что положения ч. 4 cm. 15 Конституции сформулированы не очень удачно, что этого в определенной мере касаются другие положения Конституции РФ (например, ч. 2 cm. 15), а также имеются разные виды договоров и разные виды законов. Как следствие, автор считает, что решение отдельных вопросов, которые прямо урегулированы действуюшим законодательством, должно проходить в строгом соответствии с его положениями, а те вопросы, которые вызывают юридическую коллизию, должны решаться индивидуально применительно к каждой конкретной ситуаџии Конституичонным Судом РФ или судами общей юрисдикиии, исходя из подсудности.

Ключевые слова: Международный договор, Конституция, источник международного права, источник конституционного права, конституционное право, законодательство, постановления, Конституционный Суд РФ, глобализация, проблема.
\end{abstract}

Abstract: According to the Constitution of the Russian Federation (p. 4 of the Art. 15) the international treaties form part of its legal system along with the generally recognized principles and norms of the international law. The issue regarding inclusion of the international treaties into the list of sources of constitutional law is approached from various standpoints in the Russian legal literature. As a result, in this article based upon the analysis of the scientific literature, current constitutional legislation of Russia and foreign states, as well as the relevant provisions of the Constitutional Court of the Russian Federation, the author attempts to show the place of the international treaties within the system of constitutional law. The author considers that the issues of whether the international treaties of the Russian Federation are sources of the constitutional law of the Russian Federation, whether they are directly applicable in its territory and what their legal force is have no unambiguous solutions, which is due the flawed formulations of part 4 of Art. 15 of the Constitution of the Russian Federation, while there are references to these issues in other provisions of the Constitution (e.g., part 2 of Art. 15 of the Constitution of the Russian Federation), and there are also various types of treaties and laws. As a result, the author considers that resolution of some problems, which are directly regulated by the current legislation should take place in strict conformity with their provisions, while the issues causing conflict of laws should be resolved individually with due regard to each specific situation by the Constitutional Court of the Russian Federation or by the courts of general jurisdiction based on their competence.

Keywords: International treaty, Constitution, source of international law, source of constitutional law, constitutional law, legislation, resolutions, the Constitutional Court of the Russian Federation, globalization, problem. 


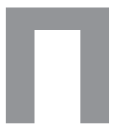
роцессы глобализации межгосударственных отношений и интернационализации конституционного права разных государств остро ставят на повестку дня исследование вопросов, связанных с проблемой взаимодействия и взаимопроникновения источников международного права и национального права. Данная проблема представляет собой определенный научный интерес не только с точки зрения международного права, но и с точки зрения конституционного права.

Особенно с учетом не очень удачной формулировки ч. 4 ст. 15 Конституции РФ: «Общепризнанные принципы и нормы международного права и международные договоры Российской Федерации являются составной частью ее правовой системы. Если международным договором Российской Федерации установлены иные правила, чем предусмотренные законом, то применяются правила международного договора».

Тем более, что ни в международном праве, ни в национальном праве разных государств эта проблема не имеет однозначного подхода к их юридическому разрешению1. Например, в Российской Федерации в соответствии с уже упомянутой статьей ее Конституции общепризнанные принципы и нормы международного права являются составной частью ее правовой системы. А во Франции этот вопрос действующая Конституция увязывает с действием международного договора на территории другой стороны: «международные договоры или соглашения, должным образом ратифицированные или одобренные, имеют силу, превышающую силу законов, с момента опубликования, при условии применения каждого соглашения или договора другой стороной» (ст. 55).

Прежде всего, следует отметить, что международные договоры образуют правовую основу межгосударственных отношений, содействуют поддержанию всеобщего мира и безопасности, развитию международного сотрудничества в соответствии с целями и принципами Устава Организации Объединенных Наций и международных региональных организаций.

Кроме того, в настоящее время международным договорам принадлежит важная роль в защите основных прав и свобод человека, в обеспечении законных

\footnotetext{
${ }^{1}$ Например, в международном праве давно сложились две монистические теории (одна из них исходит из однозначного приоритета международного права над национальным, другая наоборот) и дуалистическая теория сторонники которой считают, что международное и национальное - две относительно самостоятельные и взаимодействующие друг с другом системы права.
}

интересов государств. Российская Федерация выступает за неукоснительное соблюдение договорных и обычных норм, подтверждает свою приверженность основополагающему принципу международного права - принципу добросовестного выполнения международных обязательств.

Международные договоры - существенный элемент стабильности международного правопорядка и отношений России с зарубежными странами, функционирования правового государства. Вместе с тем международные договоры Российской Федерации наряду с общепризнанными принципами и нормами международного права являются в соответствии с Конституцией РФ составной частью ее правовой системы.

Проблема принадлежности международных договоров к источникам конституционного права не получила в отечественной литературе однозначного отношения.

Так, некоторые авторы к источникам конституционного права относят «общепризнанные принципы и нормы международного права и международные договоры Российской Федерации» ${ }^{2}$. Другие же авторы к источникам конституционного права относят только международные договоры ${ }^{3}$.

Во многом это вызвано тем обстоятельством, что «включенная в Конституцию Российской Федерации формулировка «общепризнанные принципы и нормы международного права» таит в себе много неясностей, поскольку в мире не существует общепринятого определения этих принципов и норм.

Таковыми называют принципы Устава Организации Объединенных Наций и «некоторые другие», но даже универсальное признание какой-либо нормы (т.е. подавляющим большинством государств) не порождает обязанности каждого государства соблюдать ее, если эта норма не нашла своего закрепления во внутреннем праве, в акте ратификации или в межгосударственном договоре. Поэтому многие исследователи справедливо задаются вопросом: существуют ли вообще «общепризнанные принципы и нормы международного права», a если существуют, то каково их содержание?» ${ }^{4}$.

\footnotetext{
${ }^{2}$ Конституционное право России. Курс лекций / Отв. ред. Ю.Л. Шульженко. - М., 2007. С. 32.

${ }^{3}$ См.: Конституционное право Российской Федерации: учебник для бакалавров / Отв. ред. В.И. Фадеев. - М.: Проспект, 2013. C. 33 - 34; Чиркин B.E. Конституционное право. Учебник для бакалавров - М.: МПСУ; Воронеж, 2013. С. 25.

${ }^{4}$ Баглай М.В. Конституционное право Российской Федерации: Учебник. 4-е изд. доп. и перераб. - М.: Норма, 2007. С. 36.
} 
Кроме того, если подходить к вопросу об источниках права строго формально и с юридических позиций, то под ними принято понимать «формы, посредством которых устанавливаются и получают обязательную силу правовые нормы» ${ }^{5}$. Наиболее распространенной формой являются нормативные правовые акты. Строго говоря, «общепризнанные принципы и нормы международного права» не подходят на роль источников права.

По указанной проблеме в конституционном праве России можно выделить три взаимосвязанных среза:

1. действуют ли международные договоры Российской Федерации на ее территории непосредственно;

2. как разрешать проблему противоречия между положениями международного договора и положениями закона, о которой речь идет во втором предложении ч. 4. ст. 15 Конституции РФ;

3. какова вообще юридическая сила у международного договора в национальном праве России.

Непосредственное действие международных договоров Российской Федерачии на ее территории. Основанием для придания международным договорам Российской Федерации юридической силы является «генеральная отсылка» ч. 4 ст. 15 Конституции РФ, согласно которой «общепризнанные принципы и нормы международного права и международные договоры Российской Федерации являются составной частью ее правовой системы. Если международным договором Российской Федерации установлены иные правила, чем предусмотренные законом, то применяются правила международного договора».

Указанные положения ч. 4 ст. 15 Конституции Российской Федерации были конкретизированы Федеральным законом Российской Федерации «О международных договорах Российской Федерации» (от 25 декабря 2012 г.) $)^{6}$. Согласно ч. 3 ст. 5 указанного Федерального закона положения официально опубликованных международных договоров Российской Федерации, не требующие издания внутригосударственных актов для применения, действуют в Российской Федерации непосредственно. Для осуществления иных положений международных договоров Российской Федерации принимаются соответствующие правовые акты.

\footnotetext{
${ }^{5}$ Козлова Е.И., Кутафин О.Е. Конституционное право России: Учебник. 4-е изд., перераб. и доп. - М.: Велби, Проспект, 2008. C. 25

${ }^{6}$ С3 РФ. 199. № 29. Ст. 2757.
}

Следовательно, только некоторая часть международных договоров Российской Федерации, а именно не требующих издания внутригосударственных актов для применения, теоретически могут в определенной степени считаться источниками конституционного права. Все остальные договоры, требующие издания соответствующих нормативных правовых актов органов государственной власти Российской Федерации, вступают в действие на территории Российской Федерации только после издания соответствующего нормативного правового акта, например, федерального закона о ратификации определенного международного договора.

Правда, в этом общем правиле могут быть исключения. В частности М.В. Баглай отмечает, что если предмет договора представляет для государства особый интерес, то договор до момента его ратификации и опубликования может считаться временно действующим, поскольку Конституционный Суд РФ в постановлении от 27 марта 2012 г. признал временное применение договора, затрагивающего права и свободы граждан, не противоречащим Конституции РФ, но указал, что такие договоры должны быть опубликованы?

Пленум Верховного Суда Российской Федерации Постановлением от 10 октября 2003 г. № 5 «О применении судами общей юрисдикции общепризнанных принципов и норм международного права и международных договоров Российской Федерации» разъяснил, что «к признакам, свидетельствующим о невозможности непосредственного применения положений международного договора Российской Федерации, относятся, в частности, содержащиеся в договоре указания на обязательства государств-участников по внесению изменений во внутреннее законодательство этих государств.

При рассмотрении судом гражданских, уголовных или административных дел непосредственно применяется такой международный договор Российской Федерации, который вступил в силу и стал обязательным для Российской Федерации и положения которого не требуют издания внутригосударственных актов для их применения и способны порождать права и обязанности для субъектов национального права (часть 4 статьи 15 Конституции Российской Федерации, части 1 и 3 статьи 5 Федерального закона «О международных договорах Российской Федерации», часть 2 статьи 7 ГК РФ).

\footnotetext{
${ }^{7}$ См.: Баглай М.B. Конституционное право Российской Федерации. Учебник. - 10-е изд. перераб. и доп. - М.: Норма - ИНФРА-М, 2013. С. 37.
} 
Решая вопрос о возможности применения договорных норм международного права, суды должны исходить из того, что международный договор вступает в силу в порядке и в дату, предусмотренные в самом договоре или согласованные между участвовавшими в переговорах государствами. При отсутствии такого положения или договоренности договор вступает в силу, как только будет выражено согласие всех участвовавших в переговорах государств на обязательность для них договора (статья 24 Венской конвенции о праве международных договоров 1969 г.).

Судам надлежит иметь в виду, что международный договор подлежит применению, если Российская Федерация в лице компетентных органов государственной власти выразила согласие на обязательность для нее международного договора посредством одного из действий, перечисленных в статье 6 Федерального закона «О международных договорах Российской Федерации» (путем подписания договора; обмена документами, его образующими; ратификации договора; утверждения договора; принятия договора; присоединения к договору; любым иным способом, о котором условились договаривающиеся стороны), а также при условии, что указанный договор вступил в силу для Российской Федерации (например, Конвенция о защите прав человека и основных свобод была ратифицирована Российской Федерацией Федеральным законом от 30 марта 1998 г. № 54-Ф3, а вступила в силу для Российской Федерации 5 мая 1998 г. - в день передачи ратификационной грамоты на хранение Генеральному секретарю Совета Европы согласно статье 59 этой Конвенции)» ${ }^{8}$.

Кроме того, следует иметь в виду, что об особой роли международных договоров в регулировании конституционно-правовых отношений свидетельствуют не только положения ч. 4 ст. 15 Конституции, но и положения ч. 2 ст. 15 Конституции Российской Федерации, которая установила норму в соответствии с которой «органы государственной власти, органы местного самоуправления, должностные лица, граждане и их объединения обязаны соблюдать Конституцию Российской Федерации и законы». Все без исключения субъекты, указанные в данной статье Конституции, являются субъектами конституционных правоотношений. Следовательно, если они не обязаны соблюдать международные договоры, потому что они не указаны в ч. 2 ст. 15 Конституции, то

\footnotetext{
${ }^{8}$ Бюллетень Верховного Суда РФ. 2003. № 12.
}

они и не действуют непосредственно на территории Российской Федерации. Другими словами, без их ратификации федеральными законами, международные договоры непосредственно регулировать конституционно-правовые отношения не могут.

Проблема противоречия между положениями международного договора и положениями закона также не получила однозначного разрешения. Это обстоятельство вызвано не только отсутствием прямого действия международных договоров на территории государства, о чем мы писали выше, но и тем, что в современном международном праве имеются разные виды международных договоров (межгосударственных, межправительственных, межведомственных и др.) и разные виды законов (федеральных конституционных, федеральных, законов субъектов Федерации); и у тех, и у других имеется разная юридическая сила.

В связи с тем, что ратификация международного договора Российской Федерации осуществляется федеральным законом, то с вступлением такого закона в юридическую силу одновременно приобретают юридическую силу положения международного договора и возникают противоречия между ними и положениями действовавшего до принятия федерального закона о ратификации другого закона. Указанные противоречия могут быть разрешены по принципу: более поздний по времени принятия закон о ратификации отменяет противоречащие ему положения другого закона.

О справедливости указанного замечания свидетельствуют, в частности, заключительные положения федеральных законов РФ о ратификации конкретных международных договоров, отменяющие конкретные нормы противоречащих им других федеральных законов, а также обязывающие Президента РФ и Правительство РФ в установленные сроки привести положения своих указов и постановлений в соответствие с законом о ратификации.

Таким образом, установленная ч. 4 ст. 15 Конституции РФ норма о приоритете положений международного договора Российской Федерации перед законом позволяет говорить как о приоритете применения ратифицированного международного договора (подробнее см.: ниже) перед законом, так и о приоритете закона о ратификации международного договора перед другим федеральным законом (исходя из даты их принятия).

Следует отметить, что и данное предложение также не снимает всех проблем из-за неоднозначности конституционной формулировки, разных видов международных договоров и законов. 
Например, не все договоры, заключаемые от имени Российской Федерации, утверждаются законом о ратификации. Часть из них утверждается указами Президента РФ о присоединении к договору и поэтому не имеют приоритета перед федеральным законом. Такие виды международных договоров как межправительственные и межведомственные тем более преимуществом по отношению к национальному закону не обладают.

Поскольку в соответствии со ст. 20 Федерального закона от 15 июля 1995 г. № 101-Ф3 «О международных договорах Российской Федерации» (с изменениями и дополнениями), утверждение, принятие в отношении договоров, заключаемых от имени Российской Федерации (за исключением договоров, предусмотренных подпунктом «а» пункта 2 данной статьи) осуществляются Президентом Российской Федерации, а в отношении договоров, заключаемых от имени Российской Федерации, по вопросам, относящимся к ведению Правительства Российской Федерации, - Правительством Российской Федерации; в отношении договоров, заключаемых от имени Правительства Российской Федерации, Правительством Российской Федерациия.

Применительно к законам следует согласиться с позицией, что «термин «закон» в данном случае требует расширительного истолкования: если международный договор обладает преимуществом перед законом, то тем более он обладает преимуществом перед иными нормативными правовыми актами. Речь идет как о федеральных законах, так и о законах субъектов РФ» ${ }^{10}$.

Следовательно, вопрос о противоречиях между положениями международного договора и положениями закона должны решаться исходя из вида международного договора и вида закона.

Проблема юридической силы международного договора. Такую же неоднозначную оценку получил и вопрос о юридической силе международного договора, а также о его месте в системе источников конституционного права. Например, М.В. Баглай считает, что «в иерархии источников права ратифицированный международный договор стоит выше, чем закон, поскольку нормы последнего не могут противоречить нормам такого международного договора» ${ }^{11}$.

Подобное утверждение не бесспорно. Поскольку если согласиться с ним, то тут же возникает вопрос:

\footnotetext{
${ }^{9}$ С3 РФ. 1995. № 29. С. 2757.

${ }^{10}$ Там же. С. 163.

${ }^{11}$ Баглай М.В. Конституционное право Российской Федерации. Учебник. - 10-е изд. перераб. и доп. С. 36.
}

почему юридическая сила федерального закона о ратификации выше юридической силы другого федерального закона, коль скоро оба они являются федеральными законами?

В иерархии источников конституционного права международный договор Российской Федерации может стоять выше только закона субъекта Федерации. И то при условии, что федеральные органы государственной власти не заключили такой договор по вопросам, которые в соответствии со ст. 73 Конституции РФ находятся в исключительном ведении субъектов Федерации. Если же, заключая международный договор, федеральные органы государственной власти вторглись в исключительное ведение субъектов Федерации, то в соответствии со ст. 73 Конституции РФ Конституционный Суд РФ может признать такой договор противоречащим Конституции РФ.

Видимо, в известной степени следует согласиться с тем, что Конституция РФ, «не устанавливая общий примат международно-правовых принципов и норм над внутригосударственным правопорядком, закрепляет приоритет международного договора Российской Федерации в применении, если и поскольку между ним и нормой национального закона возникла коллизия. Это означает, что нормы закона, предусматривающие иные правила, чем установленные договором, сохраняют свою юридическую силу, но не применяются при разрешении дел, касающихся государства, также участвующего в соответствующем договоре» ${ }^{12}$.

Хотя, как представляется, использование формулы: «приоритет международного договора Российской Федерации в применении» это только частичное решение проблемы. Поскольку без ратификации международный договор на территории Российской Федерации не действует, то тут не приходится говорить, ни о его применении, ни о его противоречии закону.

Не очень удачная формулировка ч. 4 ст. 15 Конституции РФ порождает еще одну очень важную юридическую неопределенность: место заключенного Российской Федерацией международного договора по отношению к самой Конституции РФ.

Думается, как и по другим подобным проблемам, здесь также необходимо комплексное правоприменение. То есть, необходимо исходить не только из поло-

\footnotetext{
${ }^{12}$ Комментарий к Конституции Российской Федерации / Под ред. В.Д. Зорькина. 2-е изд. перераб. и доп. - М.: Норма ИНФРА-М, 2011. С. 159.
} 
жений ч. 4 ст. 15 Конституции РФ, но и из содержания ч. 1 ст. 15 Конституции РФ, которая провозгласила, что «Конституция Российской Федерации имеет высшую юридическую силу, прямое действие и применяется на всей территории Российской Федерации. Законы и иные правовые акты, принимаемые в Российской Федерации, не должны противоречить Конституции Российской Федерации».

Правда, если учесть то, что «ничто не вечно под Луной», то и в этом вопросе «возможны варианты». В частности, один из таких гипотетических вариантов предусмотрен ст. 22 Федерального закона «О международных договорах Российской Федерации», предусматривающий «особый порядок выражения согласия на обязательность для Российской Федерации международных договоров». В ней установлено, что «если международный договор содержит правила, требующие изменения отдельных положений Конституции Российской Федерации, решение о согласии на его обязательность для Российской Федерации возможно в форме федерального закона только после внесения соответствующих поправок в Конституцию Российской Федерации или пересмотра ее положений в установленном порядке» ${ }^{13}$.

Как следует их процитированной нормы указанного Федерального закона, даже «особый порядок выражения согласия на обязательность для Российской Федерации международных договоров» не отменяет верховенства Конституции РФ и не может изменить
Конституцию или действовать вопреки ее положениям. Поскольку в нормативных правовых актах, включая и Конституцию РФ, невозможно наперед предусмотреть все и вся, то гипотетически может возникнуть ситуация описанная выше. В этом случае, сохраняя верховенство Конституции РФ, в нее сначала вносят соответствующую поправку и только после этого приступают к ратификации международного договора Российской Федерации ${ }^{14}$. С учетом сложного порядка внесения поправок в Конституцию, можно предположить, что указанная гипотетическая ситуация не возникнет.

Таким образом, вопрос о том, являются ли международные договоры Российской Федерации источниками конституционного права России, действуют ли они на ее территории непосредственно и какова вообще их юридическая сила не имеет однозначного решения в силу того, что положения ч. 4 ст. 15 Конституции сформулированы не очень удачно, что этого в определенной мере касаются другие положения Конституции РФ (например, упоминавшаяся ч. 2 ст. 15), а также имеются разные виды договоров и разные виды законов.

В силу этого решение той части указанных вопросов, которые прямо урегулированы действующим законодательством, должно проходить в строгом соответствии с его положениями, а те вопросы, которые вызывают юридическую коллизию, должны решаться индивидуально применительно к каждой конкретной ситуации Конституционным Судом РФ или судами общей юрисдикции, исходя из подсудности.

\section{Библиография:}

1. Баглай М.В. Конституционное право Российской Федерации: Учеб. 4-е изд. доп. и перераб. М.: Норма, 2007. С. 36.

2. Баглай М.В. Конституционное право Российской Федерации: Учеб. 10-е изд. перераб. и доп. М.: Норма - ИНФРА-М, 2013. С. 36, 37.

3. Козлова Е.И., Кутафин О.Е. Конституционное право России: Учеб. 4-е изд., перераб. и доп. М.: Велби, Проспект, 2008. С. 25.

4. Комментарий к Конституции Российской Федерации / Под ред. В.Д. Зорькина. 2-е изд. перераб. и доп. М.: Норма - ИНФРА-М, 2011. С. 159.

5. Конституционное право России: Курс лекций / Отв. ред. Ю.Л. Шульженко. М., 2007. С. 32.

\footnotetext{
${ }^{13}$ СЗ РФ. 1995. № 29. С. 2757.
}

\footnotetext{
${ }^{14}$ Кстати, подобная ситуация предусмотрена Конституцией Франции 1958 г. В статье 54 установлено: «Если Конституционный совет по запросу Президента Республики, Премьер-министра или председателя одной из палат либо 60 депутатов или 60 сенаторов заявит, что какое-либо международное обязательство содержит положение, противоречащее Конституции, то разрешение на ратификацию или одобрение этого международного обязательства может быть дано только после пересмотра Конституции».
} 
6. Конституционное право Российской Федерации: Учеб. для бакалавров / Отв. ред. В.И. Фадеев. М.: Проспект, 2013. C. 33,34 .

7. Чиркин В.Е. Конституционное право: Учеб. для бакалавров. М.: МПСУ; Воронеж, 2013. С. 25.

8. Ранчинская П.О.. Специфика взаимодействия российского и международного права в области международного коммерческого арбитража // Право и политика. - 2013. - № 10. - C. 104-107. DOI: 10.7256/1811-9018.2013.10.9581.

9. Можуга В.В. Место международных соглашений в системе публичного права Российской Федерации. Особенности иерархической зависимости различных международных соглашений в рамках ЕврАзЭС // NB: Международное право. - 2014. - № 1. - C.63-86. DOI: 10.7256/2306-9899.2014.1.10614. URL: http://e-notabene.ru/wl/article_10614.html

10. Разумов Ю.А. Некоторые конституционно-правовоые особенности реализации норм международного права в военной сфере в зарубежных странах // NB: Международное право. - 2013. - № 1. - C.171-183. DOI: 10.7256/23069899.2013.1.684. URL: http://e-notabene.ru/wl/article 684.html

11. Полтораков А.Ю.. Геостратегия современного государства: политико-экономические дилеммы // Международные отношения. - 2013. - № 3. - С. 104-107. DOI: 10.7256/2305-560X.2013.3.7954.

12. С.О. Шемшученко. Двусторонние инвестиционные соглашения: типичная структура, понятия и формулировки положений // Право и политика. - 2012. - № 12. - С. 104-107.

13. Каламкарян Р.А. Включенность Российской Федерации в деятельность Международного Суда ООН в деле обеспечения международной законности и правопорядка // NB: Международное право. - 2013. - № 2. - C.85-118. DOI: 10.7256/2306-9899.2013.2.691. URL: http://e-notabene.ru/wl/article_691.html

14. Григорьева О.Г. Теоретические основы международной правовой помощи по гражданским делам в юридической науке советского государства // NB: Международное право. - 2013. - № 1. - C.215-306. DOI: 10.7256/2306-9899.2013.1.344. URL: http://e-notabene.ru/wl/article_344.html

15. Н. Ю. Ерпылева. Международный гражданский процесс: институционно-нормативный механизм правового регулирования // Право и политика. - 2012. - № 10. - С. 104-107.

16. Н. Ю. Ерпылева. Международный гражданский процесс: институционно-нормативный механизм правового регулирования // Право и политика. - 2012. - № 9. - С. 104-107.

17. Фардеева И.Н. Роль субъектов Российской Федерации в приграничном сотрудничестве с Европейским Союзом. // NB: Международное право.-2012.-№ 1.-C.26-35.DOI: 10.7256/2306-9899.2012.1.496. URL: http://e-notabene.ru/wl/article_496.html

18. Григорьева О.Г. Участие CCCP в создании международных основ правовой помощи по гражданским делам // NB: Международноеправо.-2012.-№ 1.-C.76-115.DOI: 10.7256/2306-9899.2012.1.349. URL: http://e-notabene.ru/wl/article_349.html

19. Воронина Н.А. Союзное государство Россия - Беларусь: опыт правового регулирования // NB: Международное право. - 2013. - № 3. - C.52-67. DOI: 10.7256/2306-9899.2013.3.9061. URL: http://e-notabene.ru/wl/article_9061.html

20. Ярошкина М.Е. Роль России в развитии интеграционных процессов в Центральной Азии в рамках ЕврАзЭС// Политика и Общество, №2-2010

21. Шебанова Н.А. Международные обязательства и активы бывшего СССР: проблемы раздела и итоговое решение // NB: Международное право. - 2013. - № 3. - C.88-166. DOI: 10.7256/2306-9899.2013.3.8764. URL: http://e-notabene. ru/wl/article_8764.html

22. 22. Можуга В.В. Факторы, влияющие на иерархическую зависимость источников публичного права в Таможенном союзе // NB: Международное право. - 2013. - № 4. - C.1-15. DOI: 10.7256/2306-9899.2013.4.10104. URL: http://e-notabene.ru/wl/article_10104.htm

\section{References (transliterated):}

1. Baglai M.V. Konstitutsionnoe pravo Rossiiskoi Federatsii: Ucheb. 4-e izd. dop. i pererab. M.: Norma, 2007. S. 36.

2. Baglai M.V. Konstitutsionnoe pravo Rossiiskoi Federatsii: Ucheb. 10-e izd. pererab. i dop. M.: Norma - INFRA-M, 2013. S. 36, 37.

3. Kozlova E.I., Kutafin O.E. Konstitutsionnoe pravo Rossii: Ucheb. 4-e izd., pererab. i dop. M.: Velbi, Prospekt, 2008. S. 25.

4. Chirkin V.E. Konstitutsionnoe pravo: Ucheb. dlya bakalavrov. M.: MPSU; Voronezh, 2013. S. 25.

5. Ranchinskaya P.O.. Spetsifika vzaimodeistviya rossiiskogo i mezhdunarodnogo prava v oblasti mezhdunarodnogo kommercheskogo arbitrazha // Pravo i politika. - 2013. - № 10. - S. 104-107. DOI: 10.7256/1811-9018.2013.10.9581.

6. Mozhuga V.V. Mesto mezhdunarodnykh soglashenii v sisteme publichnogo prava Rossiiskoi Federatsii. Osobennosti ierarkhicheskoi zavisimosti razlichnykh mezhdunarodnykh soglashenii v ramkakh EvrAzES // NB: Mezhdunarodnoe pravo. - 2014. - № 1. - S.63-86. DOI: 10.7256/2306-9899.2014.1.10614. URL: http://e-notabene.ru/wl/article_10614.html

7. Razumov Yu.A. Nekotorye konstitutsionno-pravovoye osobennosti realizatsii norm mezhdunarodnogo prava v voennoi sfere v zarubezhnykh stranakh // NB: Mezhdunarodnoe pravo. - 2013. - № 1. - S.171-183. DOI: 10.7256/2306-9899.2013.1.684. URL: http://e-notabene.ru/wl/article_684.html 
DOI: $10.7256 / 2226-6305.2014 .3 .11775$

При цитировании этой статьи сноска на dоі обязательна

8. Poltorakov A.Yu.. Geostrategiya sovremennogo gosudarstva: politiko-ekonomicheskie dilemmy // Mezhdunarodnye otnosheniya. - 2013. - № 3. - S. 104-107. DOI: 10.7256/2305-560X.2013.3.7954.

9. S.O. Shemshuchenko. Dvustoronnie investitsionnye soglasheniya: tipichnaya struktura, ponyatiya i formulirovki polozhenii // Pravo i politika. - 2012. - № 12. - S. 104-107.

10. Kalamkaryan R.A. Vklyuchennost' Rossiiskoi Federatsii v deyatel'nost' Mezhdunarodnogo Suda OON v dele obespecheniya mezhdunarodnoi zakonnosti i pravoporyadka // NB: Mezhdunarodnoe pravo. - 2013. - № 2. - S.85-118. DOI: 10.7256/23069899.2013.2.691. URL: http://e-notabene.ru/wl/article 691.html

11. Grigor'eva O.G. Teoreticheskie osnovy mezhdunarodnoi pravovoi pomoshchi po grazhdanskim delam v yuridicheskoi nauke sovetskogo gosudarstva // NB: Mezhdunarodnoe pravo. - 2013. - № 1. - S.215-306. DOI: 10.7256/2306-9899.2013.1.344. URL: http://e-notabene.ru/wl/article_344.html

12. N. Yu. Erpyleva. Mezhdunarodnyi grazhdanskii protsess: institutsionno-normativnyi mekhanizm pravovogo regulirovaniya // Pravo i politika. - 2012. - № 10. - S. 104-107.

13. N. Yu. Erpyleva. Mezhdunarodnyi grazhdanskii protsess: institutsionno-normativnyi mekhanizm pravovogo regulirovaniya // Pravo i politika. - 2012. - № 9. - S. 104-107.

14. Fardeeva I.N. Rol' sub' 'ektov Rossiiskoi Federatsii v prigranichnom sotrudnichestve s Evropeiskim Soyuzom. // NB: Mezhdunarodnoe pravo. - 2012. - № 1. - S.26-35. DOI: 10.7256/2306-9899.2012.1.496. URL: http://e-notabene.ru/wl/ article_496.html

15. Grigor'eva O.G. Uchastie SSSR v sozdanii mezhdunarodnykh osnov pravovoi pomoshchi po grazhdanskim delam // NB: Mezhdunarodnoe pravo. - 2012. - № 1. - S.76-115. DOI: 10.7256/2306-9899.2012.1.349. URL: http://e-notabene.ru/wl/ article_349.html

16. Voronina N.A. Soyuznoe gosudarstvo Rossiya - Belarus': opyt pravovogo regulirovaniya // NB: Mezhdunarodnoe pravo. - 2013. - № 3. - S.52-67. DOI: 10.7256/2306-9899.2013.3.9061. URL: http://e-notabene.ru/wl/article_9061.html

17. Yaroshkina M.E. Rol' Rossii v razvitii integratsionnykh protsessov v Tsentral'noi Azii v ramkakh EvrAzES//Politika i Obshchestvo, №2-2010

18. Shebanova N.A. Mezhdunarodnye obyazatel'stva i aktivy byvshego SSSR: problemy razdela i itogovoe reshenie // NB: Mezhdunarodnoe pravo. - 2013. - № 3. - S.88-166. DOI: 10.7256/2306-9899.2013.3.8764. URL: http://e-notabene.ru/wl/ article_8764.html

19. Mozhuga V.V. Faktory, vliyayushchie na ierarkhicheskuyu zavisimost' istochnikov publichnogo prava v Tamozhennom soyuze // NB: Mezhdunarodnoe pravo. - 2013. - № 4. - S.1-15. DOI: 10.7256/2306-9899.2013.4.10104. URL: http://e-notabene.ru/wl/article_10104.htm 